\title{
Student Progress in Higher Education: What We Have Learned from Large-Scale Studies
}

\author{
Gérard Lassibille*
}

Institut de Recherche sur l'Economie de l'Education, Centre National de la Recherche Scientifique, Dijon, France

\begin{abstract}
This review examines student progress in higher education based on 28 articles examining 25 large-scale samples of first-year entrants in higher education programs in nine countries. These articles were obtained from a search of published and publicly available research on student departure. Although the results of the studies reviewed are heterogeneous, generalized trends emerge from the synthesis of this body of research on dropout behavior, completion, and time-to-degree. The vast majority of the empirical works reviewed indicate that personal characteristics, family background, prior attainment, and financial aid are important factors influencing students' progress. Although almost every empirical work estimates the impact of these variables, little attention has been directed toward understanding how university characteristics affect student departure; more research and more data clearly are needed to analyze these issues.
\end{abstract}

Keywords: Higher education, completion, withdrawal, literature review.

\section{INTRODUCTION}

Dropping out, transferring, and progressing slowly toward a degree have severe consequences for the individuals involved as well as for the society that finances most of the cost of service delivery. Having a better understanding of how students' enrollment decisions end is thus important in maximizing the use of resources allocated to education and in supporting the development of retention strategies that help to improve the education system's performance. For these reasons, numerous economic and sociological studies are devoted to completion and to students' dropout behavior [1-5].

This review summarizes the results of the literature on student progress between 1980 and 2007 and examines factors that contribute to the academic excellence of higher education students. In total 28 large-scale studies describing the school career of new entrants in higher education programs are analyzed. The results cover nine countries and 25 samples of higher education students. This review highlights various impacts that have implications for the development of education policy. Most of the studies reviewed find that personal characteristics, family background, prior attainment, and financial aid have a significant influence on student completion, time-to-degree, and withdrawal. While almost every study includes these variables as a determinant of completion or dropout, few of them address how university characteristics affect student progress and whether differences in the schooling environment are associated with variations in completion and withdrawal rates. More research and more data clearly are needed to analyze these issues. Despite this shortcoming in the research, this narrative review of the literature may be

*Address correspondence to this author at the Institut de Recherche sur l'Economie de l'Education, Pôle AAFE, Esplanade Erasme, BP 26513 21065 Dijon Cedex - France; Tel: +33 3803954 57;

E-mail: gerard.lassibille@u-bourgogne.fr suggestive for university authorities and educational planners in designing policies and initiating interventions to prevent students from leaving the higher education system before completion.

The remainder of the paper is organized as follows. Section 2 briefly describes the literature sources for our analysis. Section 3 summarizes the main findings of the studies reviewed. Section 4 draws some conclusions and policy implications.

\section{LITERATURE SOURCES}

The review consisted of all known research on student departure from higher education programs and on the determinants of graduating, dropping out, and transferring, including the determinants of time-to-degree. The review encompassed academic papers, conference presentations, book chapters, and research reports obtained from a systematic search of available databases, including Academic Search Premier, ERIC, Google Scholar, JSTOR, and Science Direct. Qualitative case studies and studies based solely on descriptive analysis are excluded from the comparison. In all, 28 large-scale studies, covering nine countries, were collected. ${ }^{1}$ The median year of publication of these studies was 2002. The vast majority of the results were based on longitudinal data; students were followed over a six-year period on average, ending the period of observation between 1995 and 2004 in 50 percent of the studies; sample sizes varied between 200 and 115,000 students.

Because micro-level data with long follow-up periods have been readily available to academic researchers in the United States, the empirical literature on student progress through higher education programs has been especially productive in this country. This search of published and publicly available research on student departure yielded only eight other countries-Australia, Finland, Greece, Italy, Spain, Sweden, the Netherlands, and the United Kingdom-

\footnotetext{
${ }^{1}$ The full list of studies reviewed is provided in the appendix.
} 
Table 1. Characteristics of Selected Studies on Student Departure from Higher Education ${ }^{\text {a }}$

\begin{tabular}{|c|c|c|c|c|c|c|c|}
\hline Country & $\begin{array}{l}\text { Number } \\
\text { of Studies }\end{array}$ & Focus $^{b}$ & $\begin{array}{l}\text { Number } \\
\text { of Studies }\end{array}$ & Sources of Data & $\begin{array}{l}\text { Number } \\
\text { of Studies }\end{array}$ & $\begin{array}{l}\text { Number of } \\
\text { Universities }\end{array}$ & $\begin{array}{c}\text { Number of } \\
\text { Studies }\end{array}$ \\
\hline United States & 18 & Completion & 17 & Specific follow-up ${ }^{c}$ & 22 & 1 & 15 \\
\hline United Kingdom & 3 & Withdrawal & 13 & 1 cohort & 15 & $2-3$ & 2 \\
\hline Australia & 1 & Transfer & 3 & 2 cohorts & 3 & All universities & 3 \\
\hline Finland & 1 & Stopout & 4 & Other & 4 & All fields of study & 2 \\
\hline Greece & 1 & Time-to-degree & 2 & Other sources ${ }^{d}$ & 6 & One field of study & 1 \\
\hline Italy & 1 & & & & & Other & 8 \\
\hline Netherlands & 1 & & & Follow-up duration ${ }^{\mathrm{e}}$ & 6 & & \\
\hline Spain & 1 & & & & & & \\
\hline
\end{tabular}

a/ See references in appendix.

b/ Many studies focus on several modes of exit.

c/ Studies based on retrospective follow-up studies of freshmen or graduates (data collected from institutional databases, administrative files, and enrollment records, among others).

d/ Household surveys, employment surveys, and national longitudinal surveys of youth.

e/ Average duration in academic years (for studies based on specific follow-up of students only).

in which similar analysis of student departure has been carried out (Table 1).

The vast majority of the empirical work reviewed is concerned with the incidence, timing, and determinants of completion and withdrawal; few studies focus explicitly on transfer and temporary leaving of students from higher education programs, known as stopout. Much of the empirical evidence on student departure relies on retrospective follow-up of one (at best, full) cohort of firstentering students at a single university; due to the relative dearth of appropriate data, very little research has been undertaken nationwide. In this review of the literature, only two of the studies we reviewed captured the system-wide behavior of students.

Most of the studies reviewed rely on enrollment records maintained at the Registrar's Office of the institution attended by the students. The databases cover several years, and in some cases they combine information from different administrative files. Apart from detailed transcript data from first year to dropout or graduation, the databases extracted from these registries also describe the personal characteristics and family background of students when they enter the university (age, gender, location, parental education), measures of their secondary educational experience (grade-point average at the time of the preuniversity exam; field of study in secondary school), and information on whether the students received financial support. Withdrawal from a course is inferred from enrollment records. Generally, students who have a period of non-enrollment between periods of enrollment are excluded from the analysis, due to data limitations. Although students may drop out at any time during the academic year, due to data limitations many studies measure time until withdrawal as the number of years from the first year of enrollment in the program. Otherwise stated, we know the year in which students drop out, but we do not know the exact date when this event occurs. Most often, dropout is defined as withdrawal from a degree program for whatever reason. In other words, if a student leaves the program before graduation and switches to another program at the same university, this student is deemed to have withdrawn; students who leave before completion and transfer to an outof-state institution are reported as dropouts. For the students who are still enrolled and have not achieved the degree by the date of the last observation, the duration is marked as censored at this point.

Various statistical models have been developed to study students' progress through their educational courses. The choice of the model is often affected by the type of data that was available to the researchers. Most studies based on longitudinal data use discrete-time hazard models to study the decision to exit the educational system via alternative routes (graduating, dropping out, transferring, or stopping out). In this case, the standard approach to modeling the hazard, $h(j)$ - that is, the conditional probability that a student will withdraw, transfer, or graduate from a program in time interval $j$ given that he has not yet left the programis to use the discrete-time analog of the continuous-time proportional hazards model with a complementary log-log (clog-log) transformation $[6,7]$ :

$\log \left\{-\log [(1-h(j)]\}=\alpha_{j}+\beta^{\prime} X\right.$,

where $X$ is a vector of time-invariant and time-varying covariates, $\beta$ is a vector of regression coefficients, and $\alpha_{j}=$ $\log \left\{-\log \left[1-h_{0}(t)\right]\right\} \quad$ is the complementary log-log transformation of the baseline hazard arising when $X=0$. In most studies, the baseline hazard is specified as a piecewiseconstant function - that is, a step function of time. Then, the full model specification is as follows: 
$\log \left\{-\log [(1-h(j)]\}=\sum_{l=1}^{J} \alpha_{l} \delta_{l}+\beta^{\prime} X\right.$,

where $\delta$ are dummy variables corresponding to each time period, $\alpha$ are parameters to be estimated, and $J$ is the last time period observed in the sample.

The model specification considered above implicitly assumes that the explanatory variables exhaust all of the sources of individual variation in the hazard rates. Obviously, this is rarely the case: individuals differ in so many ways that no finite set of covariates can capture all of the differences between them. Failure to control for any unobserved individual-specific effects that may affect the hazard functions can produce severe bias in the structural estimates of duration models [8-11]. However, many studies on students' departure do not account for unobserved heterogeneity [12-17]; others have found it to be insignificant [18].

A student graduates, transfers, drops out, or is censored - that is, he remains in education. Otherwise stated, dropping out, transferring, and graduating are reasons for students to leave the educational system. Most studies on student departure assume that the hazards of each competing risk are mutually independent ${ }^{2}$ - that is, the discrete-time proportional hazards models presented above are fitted by running separate regressions for the probability of withdrawal, transfer, and completion, treating the other events as censored [8]. To do so, the original samples are reorganized by expanding the data into person-period form and by creating destination-specific censoring indicators [7, 19]. When modeling graduation, students who have dropped out or transferred are censored at the time of dropout or transfer, while students who have not dropped out, transferred, or graduated by the end of data collection are also censored, but at the end of data collection. When modeling dropout (transfer), students who graduate are censored at graduation, those who transfer (drop out) are censored at the time of transfer (dropout), while students who have not dropped out, transferred, or graduated by the end of data collection are also censored, but at the end of data collection.

It is crucial to keep in mind that several of the variables that may affect student progress are likely to be endogenous. The endogeneity of independent variables is a problem common to all studies on student progress through higher education programs, and only a small number of them deal with potential endogeneity of the regressors [20, 21]. Controlling for endogeneity of the explanatory variables is often difficult due to data constraints. Most studies performed on the topic use data from different administrative records. Otherwise stated, the information at the disposal of the researchers is necessarily limited and refers to variables available at the time of the students' application only.

\footnotetext{
${ }^{2}$ The literature on students' withdrawal and completion is divided on the issue of dependence of the educational outcomes. For example, Desjardins, Ahlburg, and McCall [3] estimate both independent and dependent competing-risk models for the probability of stopout and completion; they find little difference between the two specifications.
}

Because the sources do not contain the necessary instruments, the vast majority of the studies reviewed are not able to control for possible endogeneity of the variables or to correct for eventual self-selection biases. Otherwise stated, the results allow researchers to identify correlations, but they do not necessarily permit them to identify causal relations between variables. This limitation is of no great consequence if interest centers on the predictive power of the variables. From this point of view, this review of the literature shows how research efforts can exploit the information that is collected by higher education institutions. It suggests that administrative records provide a rich source of data for detailed analysis of student progress and that this information may help admissions offices to predict students' eventual performance in higher education.

\section{THE EMPIRICAL EVIDENCE}

Most studies conducted on student progress through higher education programs attempt to test two alternative theories of student persistence: (a) the student integration model [5] and (b) the student attrition model [22]. The first theory suggests that the more socially and academically integrated into an educational institution a student is, the less likely that student is to drop out. The key influences on a student's successful integration into the institution include family background, personal characteristics, previous schooling, prior academic performance, and interactions between students and teachers. The student attrition model places more emphasis on the importance of factors external to the institution for the decision to remain enrolled or to leave an educational program, such as opportunities in the labor market and financial aid. Although the two models are presented as alternatives, they are largely complementary, and various authors have shown that integrating the two theoretical frameworks provides a better understanding of students' behavior.

What does the empirical evidence reveal about student progress in higher education? Table $\mathbf{2}$ summarizes the experience of empirical estimation to date. The purpose is not to provide a comprehensive survey of the research but to give an impression of the general nature of the empirical results. The discussion is based on the large-scale studies described in Table 1. Studies that do not report the coefficient estimates or the significance level of the variables are excluded from the comparison. Table 2 does not list every determinant of student departure that is included in the works reviewed; it considers only the most common factors that are used to explain completion, time-to-degree, withdrawal, or transfer: personal characteristics, academic performance, financial support, employment status, and state of the labor market. Other important factors not detailed in Table 2, such as the characteristics of the educational production process, are also included in the discussion.

\section{Personal Characteristics}

Among student characteristics, almost every empirical estimation includes gender as a determinant of completion or dropout. More often than not, no gender effect is found to be significant when considering the withdrawal decision of 
Table 2. Summary Effects of Selected Variables on Mode of Exit from Higher Education ${ }^{\text {a }}$ (Number of Studies)

\begin{tabular}{|c|c|c|c|c|c|c|c|c|c|}
\hline \multirow{3}{*}{ Variable } & \multirow{3}{*}{$\begin{array}{c}\text { Number } \\
\text { of } \\
\text { Studies }\end{array}$} & \multicolumn{4}{|c|}{ Completion $^{b}$} & \multicolumn{4}{|c|}{ Withdrawal } \\
\hline & & \multirow{2}{*}{ Total } & \multicolumn{2}{|c|}{$\begin{array}{l}\text { Statistically } \\
\text { Significant }\end{array}$} & \multirow{2}{*}{$\begin{array}{c}\text { Not } \\
\text { Significant }\end{array}$} & \multirow{2}{*}{ Total } & \multicolumn{2}{|c|}{$\begin{array}{c}\text { Statistically } \\
\text { Significant }\end{array}$} & \multirow{2}{*}{$\begin{array}{c}\text { Not } \\
\text { Significant }\end{array}$} \\
\hline & & & $\begin{array}{c}\text { Positive } \\
\text { Effect }\end{array}$ & $\begin{array}{c}\text { Negative } \\
\text { Effect }\end{array}$ & & & $\begin{array}{c}\text { Positive } \\
\text { Effect }\end{array}$ & $\begin{array}{c}\text { Negative } \\
\text { Effect }\end{array}$ & \\
\hline \multicolumn{10}{|l|}{ Personal characteristics } \\
\hline Male & 21 & 14 & 2 & 7 & 5 & 14 & 4 & 1 & 9 \\
\hline Age at enrollment & 14 & 10 & 2 & 3 & 5 & 8 & 4 & 2 & 2 \\
\hline Abilities $^{c}$ & 17 & 10 & 6 & 1 & 3 & 12 & 1 & 6 & 5 \\
\hline Social background ${ }^{\mathrm{d}}$ & 10 & 4 & 2 & - & 2 & 8 & - & 4 & 4 \\
\hline National citizen & 6 & 4 & - & 2 & 2 & 3 & 1 & 2 & - \\
\hline Delayed enrollment & 5 & 4 & - & 4 & - & 3 & 3 & - & - \\
\hline Academic performance ${ }^{e}$ & 10 & 6 & 5 & 1 & - & 8 & - & 8 & - \\
\hline Financial support ${ }^{\mathrm{f}}$ & 11 & 8 & 2 & 1 & 5 & 7 & - & 3 & 4 \\
\hline Paid work & 5 & 2 & - & 2 & - & 3 & 1 & 1 & 1 \\
\hline Unemployment rate & 6 & 4 & 1 & 2 & 1 & 4 & 1 & - & 3 \\
\hline
\end{tabular}

a/ See references in appendix. Studies that do not show the significance levels of the variables are excluded. When a study reports results separately for various subpopulations (for example, for men or women or by year of study), the directional influence of a given variable for the whole study is set to the mode value of its impacts across the various subsamples. When several components (for example, the educational level of each parent and family income) of the same characteristic (in this case, family background of the student) are included in a model, the overall impact of this characteristic is set to the mode value of the signs of each component.

$\mathrm{b}$ / Completion or time-to-degree. A positive effect increases the probability of completion or speeds progress toward a degree.

c/ Proxied by prior academic performance (for example, verbal or mathematics test scores, matriculation examination results, high school grade-point average, student's rank in high school class, and so forth).

d/ Includes variables such as family income, social and economic status, or educational background of one or both parents.

e/ Academic performance in higher education; includes variables such as grade-point average, cumulative grade-point average, or percentage of credits earned relative to the number of credits attempted.

f/ Students receiving support (for example, grants, scholarships, loans, fellowships, assistantships, and so forth) or amount of support received.

students. However, most studies show that females are more likely to graduate and earn a degree faster than males, after controlling for other factors.

Also frequently included in the various analyses on student departure is age at enrollment. Because students who are older at the time of enrollment have higher opportunity costs and a shorter time over which they may receive a benefit in return for their investment, one may expect that these students are less likely to complete their studies and have a higher probability of dropping out. In this regard, the findings are not always consistent. Most studies in Table 2 reveal no discernible effect on completion of age at entry, and, when significant, the sign of the age effect is rather ambiguous. With regard to dropping out, the results tend to confirm that older students are at higher risk of leaving before completion than younger students; however, more often this variable exerts no impact or has an unexpected effect on this mode of exit. In some cases, the impact of age is found to differ widely by field of study. For example, Lassibille and Navarro Gómez [23] show that the odds of dropping out increase by about 17 percent with each additional year of age for students enrolled in technical programs, compared to only 8 percent on average for students enrolled in other types of programs.

Students' abilities, proxied by prior academic performance (for example, verbal or mathematics test scores, matriculation examination results, high school grade-point average, student's rank in high school class) are powerful determinants of completion and dropout. Some studies show that an advantage of one standard deviation above the sample mean in the pre-university exam score can reduce the risk of dropping out up to 80 percent, ceteris paribus. In other words, reducing the entry standards to satisfy the demand for higher education from an increasing pool of secondary school leavers who are not necessarily equipped with the basic skills needed to succeed in higher education would have adverse effects. In this context, tighter selection at the entry point of higher education might be needed.

Students' family background consists of variables such as family income or social and economic status. Very often, the educational background of the parents is also included 
among the predictors of student progress; this variable accounts for the genetic ability of students and also serves as a predictor of the parents' potential market earnings that could be invested in schooling. In this regard, the empirical evidence reviewed in Table $\mathbf{2}$ shows mixed patterns. While the students' family background exerts an unambiguous and significant effect on completion and withdrawal in around half of the studies, in the rest there is no evidence of any significant influence of family background on either mode of exit. In some cases, the educational background of the parents is found to exert a non-linear effect on withdrawal, and the results show that first-generation students - that is, students whose parents did not graduate from higher education-have a higher probability of withdrawal, ceteris paribus.

A significant number of studies take account of other personal characteristics, such as nationality, or delayed enrollment in higher education. In this regard, the findings of the empirical estimations of student departure unambiguously show that students who enroll continuously after secondary school graduation are less likely to drop out and have better odds of graduating. These findings are at odds with the commonly held belief that such a pattern of enrollment is associated with socioeconomic constraints and academic marginality that are detrimental to the student's chances of graduation [12, 24, 25].

The above list of variables by no means exhausts all of the personal factors that may affect students' departure from higher education. When information is available, the empirical research also includes individual characteristics such as race, disability, athletic status, marital status, number of children, location, registration status, or students' attitudes and preferences. In this regard, the results are various, but not always consistent. To illustrate, Hackkinen and Usitalo [26] show that married or cohabiting students in the Netherlands complete their studies considerably faster than single students, while Siegfried and Stock [27], in their study on U.S. doctoral students, conclude that marital status is not related to time-to-degree. Other studies [14] show that students who are not residents of the institution's hometown are more likely to drop out than students who are residents, ceteris paribus. The intuition of this result is clear if we think about constraints on the students' available time. On average, non-resident students have to spend more time traveling and performing domestic tasks than their peers. As shown by Dolton, Marcenaro, and Navarro [28], because time allocated to these activities is not available for study, it has a negative impact on educational achievement.

\section{Academic Performance in Higher Education}

Apart from the variables discussed above, half of the studies reviewed also incorporate enrollment variables that represent information available after students have enrolled in higher education. These variables describe how well students are progressing academically at each point in time and include, among other covariates, semester grade-point averages, cumulative grade-point averages, or the percentage of credits earned relative to the number of credits attempted.
Every study in Table 2 that takes into account these variables unequivocally demonstrates that students who perform well have higher completion probabilities, graduate faster, and are less likely to drop out or to stop out than their counterparts. These findings show that how well the student is performing at the beginning of his or her schooling career is a key element in explaining progress toward the degree and that this information is probably more important in describing graduation and time-to-completion than is information related to past academic performance. One policy implication suggested by these findings is that higher education institutions could define interventions that stimulate students' effort at the beginning of their schooling career in order to help them to limit their time-to-degree.

\section{Financial Aid}

A major concern of the empirical research on students' progress is the role that financial aid programs play in enhancing graduation rates. In this regard, the results are various, and the empirical evidence is mixed. Whereas a large number of studies conclude that financial support, such as grants, scholarships, loans, or fellowships, has no significant impact on completion and dropout, a small number of empirical works [29-31] show that receipt of financial aid significantly decreases the risk of leaving before completion and undoubtedly increases the probability of graduation. According to these studies, financial support not only boosts the demand for education, by reducing the opportunity cost of studies, but also helps to increase the flow of graduates from a given cohort of entering students. However, other studies [23] show that the sensitivity of dropping out to policies that aim to support students varies widely across higher education programs. According to these authors, all else remaining the same, the relative risk of dropping out in any given year in long-cycle programs is 2.1 times greater for students without grants than for students with financial support. With an odds ratio for non-grant students of about 1.6, spending on student scholarships appears to be comparatively less effective in reducing the dropout rate in short-cycle programs.

\section{Employment Status and the State of the Labor Market}

Around one-fourth of the studies in Table $\mathbf{2}$ include students' employment status and the state of the regional labor market as determinants of students' behavior. In this regard, the results tend to indicate that students with a paid job are less likely to finish and take more time to graduate than students without a job. This is probably because they face lower opportunity costs of delay in earning their diploma and also because working while attending school reduces the amount of time available for other activities, including time to devote to studying, and adversely affects student performance [28]. Regarding the state of the regional labor market, measured through the local unemployment rate of graduates, the results tend to show that a higher unemployment rate does not decrease the risk of dropping out, whereas poorer labor market prospects reduce the incentives to finish and increase the time-to-degree. A natural explanation is that, when a large number of jobs are 
available, the student's time opportunity cost of forgone earnings is higher, leading to greater graduation rates and faster progress toward a diploma.

\section{Characteristics of the Educational Production Process}

Some studies have addressed how university characteristics affect student departure and whether differences in the schooling environment are associated with variations in completion and withdrawal rates. In most cases, the empirical evidence is mixed. For example, Bowen and Rudenstine [32] find that program size has a negative impact on time-to-degree. The negative impact of program size on progress toward a degree may arise from the combined influences of (a) differences in the tangible schooling environment, as reflected, for example, in a higher studentteacher ratio in larger programs, and (b) differences in the effectiveness with which the available inputs are managed to promote student learning, as reflected, for example, by fewer personal interactions between students and teachers in larger programs. In contrast, this conclusion is not supported by the findings of Arulampalam, Naylor, and Smith [18] and Siegfried and Stock [27], who find no evidence of scale effect. When information on the quality of the institutions is available, the results also show that there is no consistent relationship between the quality or prestige of the program, measured through published measures of institutional rankings, and students' progress [27, 32]. Other authors relate students' behavior to common inputs into the educational process. For example, when analyzing dropping out from U.K. medical schools, Arulampalam, Naylor, and Smith [18] include teacher qualification and unit cost as determinants of the decision to withdraw. A surprising finding is that students enrolled in universities with higher levels of expenditure on salaries have higher attrition rates, while teacher qualification, proxied by the proportion of higher-quality teachers, appears to lower significantly the probability of dropout.

Finally, this review of the literature has shown that, after controlling for ability, preferences, socio-economic characteristics, performance at the beginning of the schooling career, and program size, significant differences do exist across subject areas. Some studies have shown that graduates in health, arts, and sciences finish significantly faster than students in economics and engineering, with estimated time saving varying between 0.4 and 2.3 years, depending on the type of program. This finding raises important questions about the management of the pedagogical processes in the various fields of study. In this regard, the remaining disparities in performance across subjects may be telltale signs of differences in the effectiveness with which the available educational inputs are managed to promote student learning and how teachers use their instructional time and manage their classes. They also may be attributable to the specificities of the subject matter, which can be more or less difficult depending on the field of study. More research and more data clearly are needed to analyze these issues.

\section{CONCLUSION}

This paper has summarized the most recent literature on student progress through higher education programs. In total,
28 large-scale studies describing the school career of new entrants in higher education were analyzed. Given the heterogeneity in the results presented above, caution is obviously needed in transferring the lessons to other countries. However, this review found some factors that are undoubtedly successful in predicting completion, time-todegree, or withdrawal. The vast majority of studies reviewed show that, all else remaining the same, there is a significant gender effect among students and that male students are more likely to drop out than their female counterparts. A noteworthy feature in the results is that pre-enrollment academic abilities are a significant determinant of the students' progress. This means that relaxing the entry standards into higher education, under demand pressure, could increase the time-to-degree and the probability of dropping out and consequently raise the costs of service delivery. Most studies find that age at enrollment is positively associated with slow progress toward the degree and that delaying entry to higher education could exert a significant influence on withdrawal. This review clearly showed that, all else remaining the same, academic performance and integration at the beginning of the program are key elements in explaining progress toward the degree and that this information is probably more important in describing completion or time-to-degree than is information relating to past academic performance.

Several implications for the development of education policy arise from the foregoing results. The first is the need for continued efforts to promote faster progress toward a degree. In this regard, universities could design and develop graduation interventions for at-risk students; such targeted programs would benefit both the students and the institutions. One main implication from this review is that any academic support plan designed to prevent dropping out and to reduce the time-to-degree of at-risk students should try to stimulate their effort and performance from the beginning of their schooling career. Policy makers could also consider administrative measures such as more systematic and tighter criteria for selecting the intake into higher education. Strict measures designed to limit the excessive length of time students are allowed to complete their courses should be considered too. These interventions could improve the system's performance. In the context of a meaningful expansion in the number of high school graduates, these interventions could also be one way to manage the increased pressures put on the higher education system. But equally relevant could be measures that encourage greater costconsciousness among individuals and their families as they make educational choices at the higher education level, including greater cost sharing by students in public higher education, with appropriate features to minimize any adverse impact on those from low-income families.

\section{ACKNOWLEDGEMENT}

The research was funded through a research support grant from the Government of Andalusia (no. P09SEJ4859). The opinions expressed in this paper are those of the author alone and should not be attributed to the institutions with which he is associated. 


\section{APPENDIX}

\section{List of Studies Reviewed}

\begin{tabular}{|c|c|c|c|c|c|c|c|c|}
\hline \multirow[b]{2}{*}{ Study } & \multirow[b]{2}{*}{ Country } & \multirow{2}{*}{$\begin{array}{l}\text { Survey } \\
\text { Period }\end{array}$} & \multirow{2}{*}{$\begin{array}{c}\text { Sample } \\
\text { Size }\end{array}$} & \multicolumn{5}{|c|}{ Event under consideration } \\
\hline & & & & Graduation & Withdrawal & Transfer & Stopout & $\begin{array}{c}\text { Time-to- } \\
\text { Degree }\end{array}$ \\
\hline Ahlburg, McCall, Na [21] & United States & 1979 & 4,944 & $\mathrm{X}$ & $\mathrm{X}$ & & & \\
\hline Aina [33] & Italy & 1994-2001 & 1,483 & & $\mathrm{X}$ & & & \\
\hline Arulampalam, Naylor, Smith [18] & United Kingdom & $1985-1994$ & 7,789 & & $\mathrm{X}$ & & & \\
\hline Booth, Satchell [2] & United Kingdom & $1980-1986$ & 484 & $\mathrm{X}$ & $\mathrm{X}$ & & & \\
\hline Bozick, DeLuca [12] & United States & $1992-2000$ & 11,366 & $\mathrm{X}$ & & & & \\
\hline Chizmar [13] & United States & $1983-1993$ & 813 & & $\mathrm{X}$ & & & \\
\hline Deike [14] & United States & $1990-2002$ & 3,202 & $\mathrm{X}$ & & & & \\
\hline Desjardins, Ahlburg, McCall [3] & United States & 1986-1993 & 3,975 & & $\mathrm{X}$ & & $\mathrm{X}$ & \\
\hline Desjardins, Ahlburg, McCall [34] & United States & $1986-1993$ & 3,975 & & & & $\mathrm{X}$ & \\
\hline Desjardins, Ahlburg, McCall [35] & United States & 1991-1997 & 3,070 & $\mathrm{X}$ & & & $\mathrm{X}$ & \\
\hline Desjardins, Ahlburg, McCall [36] & United States & 1984-1991 & 12,648 & $\mathrm{X}$ & & & $\mathrm{X}$ & \\
\hline Ehrenberg, Mavros [37] & United States & $1962-1986$ & 1,676 & $\mathrm{X}$ & $\mathrm{X}$ & & & \\
\hline Guerin [38] & United States & 1991-1995 & 1,288 & $\mathrm{X}$ & $\mathrm{X}$ & $\mathrm{X}$ & & \\
\hline Hackkinen, Usitalo [26] & Finland & 1985-1999 & 72,000 & $\mathrm{X}$ & & & & $\mathrm{X}$ \\
\hline Ishitani [39] & United States & $1995-2000$ & 1,747 & & $\mathrm{X}$ & & & \\
\hline Ishitani, Desjardins [40] & United States & 1989-1994 & 3,450 & & $\mathrm{X}$ & & & \\
\hline Kalamatianou, McClean [41] & Greece & 1984-1997 & 10,313 & $\mathrm{X}$ & & & & \\
\hline Lassibille, Navarro Gómez [23] & Spain & 1996-2004 & 6,991 & & $\mathrm{X}$ & & & \\
\hline Light, Strayer [42] & United States & 1979 & 7,077 & $\mathrm{X}$ & & & & \\
\hline Löfgren, Ohlsson [43] & Sweden & 1993-1996 & 181 & $\mathrm{X}$ & & & & \\
\hline Mongold et al. [44] & United States & $1995-1998$ & 2,598 & $\mathrm{X}$ & $\mathrm{X}$ & & & \\
\hline Pascarella, Terenzini [45] & United States & $1976-1977$ & 763 & & $\mathrm{X}$ & & & \\
\hline Ronco [15] & United States & $1987-1994$ & 1,635 & $\mathrm{X}$ & $\mathrm{X}$ & $\mathrm{X}$ & & \\
\hline Shah, Long, Burke [16] & Australia & $1997-2001$ & 115,526 & $\mathrm{X}$ & $\mathrm{X}$ & & & \\
\hline Siegfried and Stock [27] & United States & 1996 & 618 & & & & & $\mathrm{X}$ \\
\hline Smith, Naylor [46] & United Kingdom & $1989-1993$ & 76,258 & & $\mathrm{X}$ & & & \\
\hline Van Ours, Ridder [47] & Netherlands & 1993-1998 & 200 & $\mathrm{X}$ & $\mathrm{X}$ & & & \\
\hline Xiao [17] & United States & $1987-1993$ & 524 & $\mathrm{X}$ & & & & \\
\hline
\end{tabular}

\section{REFERENCES}

[1] Blanchfield W. College dropout identification: an economic analysis. J Hum Resour 1972; 7(4): 540-44.

[2] Booth AL, Satchell SE. The hazards of doing a PhD: an analysis of completion and withdrawal rates of British PhD students in the 1980s. J R Stat Soc A 1995; 158: 297-318.

[3] Desjardins SL, Ahlburg DA, McCall BP. An event history model of student departure. Econ Educ Rev 1999; 18: 375-90.

[4] Mallete BI, Cabrera AF. Determinants of withdrawal behavior: an exploratory study. Res High Educ 1991; 32(2): 179-94.

[5] Tinto V. Leaving college: Rethinking the causes and cures of student attrition. Chicago, IL: University of Chicago Press 1987.

[6] Cox DR. Regression models and life tables. J Roy Stat Soc B, Ser B 1972; 34: 187-202.

[7] Prentice R, Gloeckler L. Regression analysis of grouped survival data with application to breast cancer data. Biometrics 1978; 34: 57-67.
[8] Allison PD. Event history analysis. Newbury Park, CA: Sage 1984.

[9] Lancaster $T$. The econometric analysis of transition data Cambridge: Cambridge University Press 1990.

[10] Sheps MC, Menken JA. Mathematical models of conception and birth. Chicago, IL: University of Chicago Press 1973.

[11] Vaupel JW, Yashin AI. Heterogeneity's ruses: some surprising effects of selection on population dynamics. Am Stat 1985; 39: 176-85.

[12] Bozick R, DeLuca S. Better late than never? Delayed enrollment in the high school to college transition. Soc Forces 2005; 84(1): 53154.

[13] Chizmar J. A discrete-time hazard analysis of the role of gender in persistence in the economics major. J Econ Educ 2000; 31(2): 10718

[14] Deike RC. A study of college student graduation using discretetime survival analysis. PhD [dissertation]. State College (PA): Pennsylvania State University 2003. 
[15] Ronco S. How enrollment ends: analyzing the correlates of student graduation, transfer, and dropout with a competing-risk model. Tallahassee, FL: Association for Institutional Research 1996. Professional File No. 61.

[16] Shah C, Long M, Burke G. Student flows: post-initial higher education coursework programmes. Canberra: Australian Government, Department of Education, Science, and Training 2004.

[17] Xiao B. Using discrete-time survival analysis to examine time to master of science degree attainment: 37th Annual Forum of the Association for Institutional Research. Lake Buena Vista, FL 1997.

[18] Arulampalam W, Naylor RA, Smith JP. A hazard model of the probability of medical school dropout in the United Kingdom. Bonn: IZA 2001. IZA Discussion Paper No. 333.

[19] Meyer BD. Unemployment insurance and unemployment spells. Econometrica 1990; 58: 757-82.

[20] Alon S. The influence of financial aid in leveling group differences in graduating from elite institutions. Econ Educ Rev 2007; 26(3): 296-311.

[21] Ahlburg DA, McCall BP, Na I. Time to dropout from college: a hazard model with endogenous waiting. University of Minnesota 2002. Industrial Relations Center Working Paper No. 01-02.

[22] Bean JP. Dropouts and turnover: the synthesis and test of a causal model of attrition. Res High Educ 1980; 12: 291-319.

[23] Lassibille G, Navarro Gómez, $M^{a}$ L. Why do higher education students drop out? Evidence from Spain. Educ Econ 2008; 16(1): 89-105.

[24] Hearn J. Emerging variations in postsecondary attendance patterns: an investigation of part-time delayed and nondegree enrollment. Res High Educ 1992; 33: 657-87.

[25] Jacobs JA, King RB. Age and college completion: a life-history analysis of women aged 15-44. Soc Educ 2002; 75: 211-30.

[26] Hackkinen I, Usitalo R. The effect of student aid reform on graduation times: a duration analysis. Uppsala: Uppsala University, Department of Economics 2003. Working Paper No. 2003-8.

[27] Siegfried JJ, Stock WA. So you want to earn a $\mathrm{PhD}$ in economics? How long do you think it will take? J Hum Resour 2001; 36(2): 364-78.

[28] Dolton P, Marcenaro O, Navarro L. The effective use of student time: a stochastic frontier production function case study. Econ Educ Rev 2003; 22: 547-60.

[29] Cabrera AF, Nora A, Castañeda MB. The role of finances in the persistence process: a structure model. Res High Educ 1992; 33(5): 571-93.

[30] Dynarski SM. Does aid matter? Measuring the effect of student aid on college attendance and completion. Cambridge, MA: National Bureau for Economic Research 1999. NBER Working Paper No. 7422.
[31] Edlin A. Is college financial aid equitable and efficient? J Econ Perspect 1993; 7(2): 143-58.

[32] Bowen WG, Rudenstine NL. In pursuit of the PhD. Princeton, NJ: Princeton University Press 1992.

[33] Aina C. Parental background and college dropout: evidence from Italy. Pavia: University of Pavia, Department of Economics and Quantitative Methods 2005.

[34] Desjardins SL, Ahlburg DA, McCall BP. A temporal investigation of factors related to timely degree completion. J High Educ 2002; 73(5): 555-81.

[35] Desjardins SL, Ahlburg DA, McCall BP. Simulating the longitudinal effects of changes in financial aid on student departure from college. J Hum Resour 2002; 37(3): 653-79.

[36] Desjardins SL, Ahlburg DA, McCall BP. The effect of interrupted enrollment on graduation from college: racial, income, and abilities differences. Econ Educ Rev 2006; 25(6): 575-90.

[37] Ehrenberg GR, Mavros PG. Do doctoral students' financial patterns affect their time-to-degree and completion probability? J Hum Resour 1995; 30: 581-609.

[38] Guerin K. Tracking students' exit, transfer, and graduation: an event history analysis of competing risks: 37th Annual Forum of the Association for Institutional Research, Orlando, FL 1997.

[39] Ishitani T. A longitudinal approach to assessing attrition behavior among first-generation students: time-varying effects of pre-college characteristics. Res High Educ 2003; 44(4): 433-49.

[40] Ishitani T, Desjardins S. A longitudinal investigation of dropout from college in the United States: 42nd Annual Forum of the Association for Institutional Research, Toronto, Canada 2002.

[41] Kalamatianou A, McClean S. The perpetual students: Modeling duration of undergraduate studies based on lifetime-type education data. Lifetime Data Anal 2003; 9: 311-30.

[42] Light A, Strayer W. Determinants of college completion: School quality or student ability? J Hum Resour 2000; 35(2): 299-332.

[43] Löfgren $C$, Ohlsson $H$. What determines when undergraduates complete their theses? Evidence from two economics departments. Econ Educ Rev 1999; 18: 79-88.

[44] Mongold W, Bean L, Adams D, Schwab W. Who goes? Who stays? An assessment of the effect of a freshman monitoring and unit registration program on college persistence. J Coll Retent 2003; 4(1): 95-122.

[45] Pascarella E, Terenzini P. Predicting freshman persistence and voluntary dropout decisions from a theoretical model. J High Educ 1980; 51(1): 60-75.

[46] Smith J, Naylor R. Determinants of degree performance in U.K. universities: a statistical analysis of the 1993 student cohort Oxford B Econ Stat 2001; 63(1): 29-60.

[47] Van Ours JC, Ridder G. Fast track or failure: A study of the graduation and dropout rates of $\mathrm{PhD}$ students in economics. Econ Educ Rev 2003; 22: 157-166.

(C) Gérard Lassibille; Licensee Bentham Open.

This is an open access article licensed under the terms of the Creative Commons Attribution Non-Commercial License (http://creativecommons.org/licenses/by-nc/ 3.0/) which permits unrestricted, non-commercial use, distribution and reproduction in any medium, provided the work is properly cited. 